\title{
Reactive strength index during single-leg vertical continuous jumps after anterior cruciate ligament reconstruction: cross-sectional study
}

Kenji Hirohata ( $\sim$ hirohata.spt@tmd.ac.jp )

Tokyo Medical and Dental University

Junya Aizawa

Juntendo University

Takehiro Ohmi

Tokyo Medical and Dental University

Shunsuke Ohji

Tokyo Medical and Dental University

Sho Mitomo

Tokyo Medical and Dental University

Toshiyuki Ohara

Tokyo Medical and Dental University

Hideyuki Koga

Tokyo Medical and Dental University

Kazuyoshi Yagishita

Tokyo Medical and Dental University

Tetsuya Jinno

Dokkyo Medical University

Atsushi Okawa

Tokyo Medical and Dental University

\section{Research Article}

Keywords: ACL tear, vertical jump performance, asymmetry

Posted Date: January 20th, 2022

DOI: https://doi.org/10.21203/rs.3.rs-1236808/v1

License: (c) (i) This work is licensed under a Creative Commons Attribution 4.0 International License. Read Full License 


\section{Abstract \\ Background}

The association of the reactive strength index (RSI) during single-leg vertical continuous jumps (SVCJs) with single-leg hop tests in athletes after anterior cruciate ligament reconstruction (ACLR) is unclear. Thus, this study aimed to confirm the measurement properties of the RSI during SVCJs in athletes with ACLR at the phase of determining the timing of their return to sport.

\section{Methods}

RSI during SVCJs and single-leg hop (single, triple, and crossover) tests were measured for post-ACLR and healthy athletes. The limb symmetry index (LSI) was calculated using the measurements of each parameter. For each test, patients were divided into two subgroups according to their LSI score ( $\geq 90 \%$, satisfactory; $<90 \%$, unsatisfactory). Fisher's exact test was used to examine the association of single-leg hop tests with RSI during the SVCJs.

\section{Results}

A total of 21 post-ACLR and 17 healthy athletes completed all the tests. RSI during SVCJs were significantly lower on the involved limb than on the uninvolved limb in post-ACLR athletes $(P<0.001)$. The LSI of RSI during SVCJs of post-ACLR athletes were significantly lower than that of the healthy athletes $(P<0.01)$. Among the post-ACLR athletes, $<30 \%$ of those with LSIs $>90 \%$ in the single-leg hop tests had an LSI $>90 \%$ of the RSI during SVCJs.

\section{Conclusions}

RSI during SVCJs of post-ACLR athletes was significantly lower on the involved limb than on the uninvolved limb, and the asymmetry was more remarkable in the SVCJs than in the single-leg hop tests.

\section{Background}

Recently, there has been a worldwide consensus that the timing of an athlete's return to sport is not only decided by time-based criteria but also by performance-based criteria after an anterior cruciate ligament (ACL) injury and reconstruction [1-3]. Single-leg hop tests are among the primary tests and form part of the criteria for determining an athlete's return to sport [4]. They include several tasks that involve hopping on a single leg to assess distance or speed $[5,6]$. Of the traditional single-leg hop tests, three measure hopping distance: single hop for distance (SHD), triple hop for distance (THD), and crossover hop for distance (CHD) [6]. Single-leg hop tests, conducted periodically beginning 3 months after an ACL reconstruction (ACLR), can help monitor an athlete's recovery [7].

Hop symmetry is assessed using the limb symmetry index (LSI) [8]. In athletes, an LSI above $90 \%$ for single-leg hop tests is one of the leading criteria for determining their return to sport after an ACLR [9]. After an ACLR, the LSI of the SHD has been reported to increase earlier than in other outcome measures, such as muscle strength [7]. These findings suggest that the LSIs of single-leg hop tests alone may overestimate the involved limb's function after an ACLR. 
After an ACLR, jump height during single-leg vertical continuous jumps (SVCJs) is a parameter that can detect lower limb asymmetry in the single-leg jump performance of an athlete who is at the stage of potentially returning to sport [10]. Unlike the single-leg hop tests, SVCJs are not forward jumps; they involve continuous vertical jumps at the fastest pace possible $[10,11]$. Myer et al. reported that the jump height during SVCJs of the involved limb of athletes was lower than that of the uninvolved limb over 8 months after ACLR [10]. Vertical jumps are frequently required in movements such as rebounding in basketball or blocking in volleyball [12, 13]. However, no generalized measurement protocol has been established to evaluate an athlete's vertical jumping ability in the return to sport criteria after ACLR $[14,15]$.

In the study by Myer et al., one of the analyzed parameters was the jump height during SVCJs [10]. In their study, ground contact time was not analyzed although it is typically analyzed in SVCJs in addition to jump height when assessing jumping ability [16]. During tasks such as SVCJs, the duration of the contact time is related to the ground reaction force produced during the task [17]. Analyzing both the contact time and jump height in SVCJs will increase the likelihood of detecting asymmetry in the single-leg jumping ability.

In previous studies on healthy athletes, the reactive strength index (RSI), which is calculated using jump height and contact time, was used as a parameter for determining jumping ability in SVCJs [18, 19]. However, no studies have investigated the RSI during SVCJs in athletes who have undergone an ACLR. Moreover, no studies have compared the LSI of the RSI during SVCJs between post-ACLR and healthy athletes. In addition, the association of the LSI of the RSI during SVCJs with the LSI of the single-leg hop tests in athletes after ACLR is unclear.

Thus, this study aimed to confirm the properties of the RSI during SVCJs to detect asymmetry in the single-leg jumping performance of post-ACLR athletes to determine the appropriate time to return to sport. Our hypotheses were as follows: (1) the RSI scores during SVCJs and single-leg hop tests of the ACL-reconstructed limb will be significantly lower than that of the contralateral limb. (2) The LSI scores of the RSI during SVCJs and single-leg hop tests will be significantly lower in post-ACLR athletes than in healthy athletes. (3) The LSI scores of the RSI during SVCJs and single-leg hop tests are related; however, among those with $\geq 90 \%$ score in the LSI of single-leg hop tests, some will have $<90 \%$ score in the LSI of the RSI during SVCJs.

\section{Methods}

\section{Participants}

In this study, we recruited athletes who had undergone a primary ACLR between July 2017 and March 2019 and healthy athletes aged 16-45 years at the time of measurement. The inclusion criteria for post-ACLR athletes were as follows: (1) participated in team sports that required multidirectional movements and jump landing (e.g., basketball, soccer, and lacrosse) with a modified Tegner activity scale socre [20] of >6 before the injury; (2) had undergone reconstruction at least 5 months ago; and (3) had undergone reconstruction using a bone-patellar tendon-bone graft, semitendinosus tendon, or semitendinosus tendon with additional gracilis tendon. Participants who had concomitant meniscal injuries were not excluded. The exclusion criteria for post-ACLR athletes were as follows: (1) had not participated in sports because of social reasons such as pregnancy and employment, (2) had an ACL injury to the contralateral knee or ACL re-injury to the reconstructed knee, (3) had a cartilage injury and/or other ligament injuries requiring surgery, and (4) had an injury that affected the physical function of the lower back or limb. 
Healthy athletes were included in the study if they participated in a team sport that required multidirectional movements and jump-landing (e.g., basketball, soccer, and lacrosse) with a modified Tegner activity scale score of $>6$. Healthy athletes with a previous ACL injury that required reconstruction and an injury that affected the physical function of the lower back or limb were excluded.

\section{Surgical technique}

All surgeries were performed by orthopedic surgeons specialized in the knee joint. All ACLR athletes had a bonepatellar-bone or semitendinosus graft. An anatomical double-bundle reconstruction was performed using a semitendinosus tendon. If the semitendinosus graft alone was insufficient, the gracilis tendon was added.

\section{Postoperative rehabilitation protocols}

All ACLR athletes received postoperative rehabilitation in accordance with the following protocol. However, squatting with a knee flexion beyond $90^{\circ}$ was contraindicated in ACLR athletes who had undergone repair of the middle-posterior segment of the meniscus.

In the first weeks following reconstruction, ACLR athletes were encouraged to rest and limit activities of daily living to reduce knee swelling. Use of a knee brace (Straighten Position Knee-Joint Immobilizer, ALCARE, Tokyo, Japan) and crutches were discontinued 4 weeks after reconstruction. Knee range of motion exercises from full extension to $120^{\circ}$ of flexion started on the second day after reconstruction. Closed kinetic chain exercises such as weight shifting and squatting started between 1 and 2 weeks after reconstruction.

Jogging drills started at 3 months after reconstruction in athletes who had fulfilled the criterion of an LSI score of $65 \%$ of the knee extension strength at $60 \%$ s. Once $80 \%$ of a subjective full-speed running ability was achieved, sport-specific exercises were initiated with detailed instructions. Participation in sport games was allowed at 6 months after reconstruction. The decision on return to sport was made by the treating surgeon based on the following criteria: no problematic symptoms in the knee joint, full range of motion, sufficient knee isokinetic flexion/extension strength at $60 \%$ s (LSI > 85\%), and sufficient single-leg hop ability measured by the single-leg SHD (LSI of the distance $>85 \%$ ) after the athletes completed the specified athletic training.

\section{Demographic characteristics and sports activity level}

On the same testing day, age, sex, height, and weight were recorded. The sports activity level was graded using the modified Tegner activity scale [20]. To score the modified Tegner activity scale, we checked the status of the healthy athletes and the pre-injury status of the ACLR athletes. The grades of futsal (lower division), lacrosse (lower division), and lacrosse (recreational level) were 8, 8, and 7, respectively.

\section{Single-leg hop tests}

The following single-leg hop tests were performed: SHD, THD, and CHD [5]. Participants started each test with the lead toe behind a clearly marked starting line. No restrictions were placed on arm movement or gaze direction during the tests.

For a hop to be deemed successful, the landing had to be maintained. An unsuccessful hop was classified by any of the following: landing with an early touchdown of the contralateral limb, loss of balance, or an additional hop on landing. If the hop was unsuccessful, it was repeated. Participants were instructed to wear the footwear they would normally use during their training and sporting activities. 
For the SHD, participants were instructed to stand on the limb to be tested, hop forward as far as possible, and land

on the same limb $[5,6]$. The distance from the starting line to the point of heel contact of the participant's test limb upon completing the single hop was measured and recorded $[8,21]$. For the THD, participants were instructed to stand on the limb to be tested, perform three consecutive maximal forward hops, and land on the same limb [5, 6]. For the CHD, participants were instructed to stand on the limb to be tested, perform three consecutive maximal forward hops while alternately crossing over a $15-\mathrm{cm}$ marking strip on the floor [6]. When measuring the right limb, participants began the test by standing on the right limb on the right side of the line [21]. For the THD and CHD, the distance from the starting line to the point of heel contact of the participant's test limb after completing the third hop was measured and recorded [21].

For each hop test, participants were initially given a verbal description of the test, and they were allowed to perform practice trials until they were confident to perform the test. Two trials were measured and recorded; the largest of the two was used for analysis.

\section{SVCJs for measuring the RSI}

For the SVCJs test, each participant was instructed to jump as high as possible with as little ground time as possible, land under control, recover his or her balance, and repeat the vertical jump 15 times. The SVCJs test was performed twice. From our pilot study, the within-session intraclass ability of the single-leg RSI measures using the described testing methods demonstrated high reliability. The intraclass correlation coefficient (1.1) values ranged from 0.83 to 0.96 .

The Optojump Next system (Microgate, Bolzano, Italy) was used to measure the contact and flight time using a sampling rate of $1000 \mathrm{~Hz}$. The system automatically calculates the jump height from the flight time using the following equation: jump height $(m)=9.81 \times$ flight time ${ }^{2} / 8[22,23]$. The unit of jump height was converted from meters to centimeters. The contact time and jump height were calculated from the average data of the middle 5 of the 15 jumps obtained during the test. The RSI was calculated based on the following equation: reactive strength index = jump height (cm) / contact time $(\mathrm{s})[18,24]$.

\section{Calculation of the limb symmetry index}

In post-ACLR athletes, the LSI for each measurement variable was calculated by dividing the values of the involved limb by that of the uninvolved limb. In healthy athletes, the LSI of each measurement variable was calculated by dividing the values of the poorly performing limb by that of the well-performing limb. The LSI is expressed as a percentage value [25].

\section{Statistical Analysis}

All statistical analyses were performed using SPSS version 23.0 (SPSS, Chicago, IL, USA). Demographic statistics were generated for all variables. Paired t-tests were used to evaluate differences in measurement values of the limbs in both post-ACLR and healthy athletes. Independent t-tests were performed to assess differences in the LSI of each test between post-ACLR and healthy athletes. Effect sizes were determined using Cohen's d method, which defines $0.2,0.5$, and 0.8 as small, medium, and large, respectively [25].

For each test, patients were divided into two subgroups according to their LSI score ( $\geq 90 \%$, satisfactory; $<90 \%$, unsatisfactory) [9]. To examine the association of single-leg hop tests with the RSI during the SVCJs test, frequency distribution tables $(2 \times 2)$ were constructed and Fisher's exact test was used to test for significant associations. Statistical significance was set at $P<0.05$. 
All power analyses were performed using G*power statistical software. For within-subject analyses, a priori power analysis using data from a pilot test ( $n=10$; involved limb RSI, $0.43 \pm 0.14$; uninvolved limb RSI, $0.52 \pm 0.13$; effect size, Cohen's $d=0.665$; alpha $=0.05$; power $=0.80$; two-tailed) revealed that at least 20 post-ACLR athletes were required to achieve an alpha of 0.05 and a power of 0.80 . To compare the LSIs of the post-ACLR and healthy athletes, a power analysis using data from a previous study [26] with single-leg hop tests (SHD, THD, and CHD) revealed that at least 16 participants were required to achieve an alpha of 0.05 and a power of 0.80 .

\section{Results}

\section{Participants}

In this study, 21 post-ACLR and 17 healthy athletes completed the single-leg hop and SVCJs tests. The demographics of the participants are shown in Table 1. For the post-ACLR athletes, the mean duration after reconstruction was $11.6 \pm 6.9$ (range, 6.7-31.2) months. 
Table 1

Participants' demographics

\begin{tabular}{|c|c|c|c|}
\hline & ACLR athletes & Healthy athletes & \\
\hline & $n=21$ & $\mathrm{n}=17$ & $P$ value \\
\hline Age at measurement, year & $20.9 \pm 3.6(16-30)^{a}$ & $19.8 \pm 2.8(16-27)^{a}$ & n.s. \\
\hline \multicolumn{4}{|l|}{ Sex, n (\%) } \\
\hline Male & $5(23.8)$ & $5(29.4)$ & n.s. \\
\hline Female & $16(76.1)$ & $12(70.6)$ & \\
\hline Modified Tegner activity score & $7.3 \pm 0.2(6-10)^{a}$ & $7.8 \pm 0.2(7-10)^{a}$ & n.s. \\
\hline \multicolumn{4}{|l|}{ Graft type, n(\%) } \\
\hline semitendinosus tendon graft & $16(76.1)$ & - & \\
\hline semitendinosus with additional gracilis tendon & $2(9.5)$ & - & \\
\hline bone-patellar tendon-bone graft & $3(14.3)$ & - & \\
\hline \multicolumn{4}{|l|}{ Meniscus injury, n (\%) } \\
\hline Yes & $17(80.9)$ & - & \\
\hline No & $4(19.0)$ & - & \\
\hline \multicolumn{4}{|l|}{ Meniscus treatment, $\mathrm{n}(\%)$} \\
\hline Lateral meniscus & $13(61.9)$ & - & \\
\hline Medial meniscus & $8(38.1)$ & - & \\
\hline None & $3(14.3)$ & - & \\
\hline Time from surgery to measurement, month & $11.6 \pm 6.9(6.7-31.2)^{a}$ & - & \\
\hline
\end{tabular}

\section{Side-to-side differences within individuals by group}

The results of the within-subject analysis are shown in Table 2. In the post-ACLR athletes, the distance of the single-leg hop tests and RSI during the SVCJs test of the involved limb was significantly lower than that of the uninvolved limb. Compared with the single-leg hop tests, the RSI during the SVCJs test showed a higher effect size. In healthy athletes, the distance of the single-leg hop tests and RSI during the SVCJs test was significantly lower in the poor-performing limb than in the well-performing limb.

\section{Comparison of the LSIs of post-ACLR and healthy athletes}

The LSIs of each test are shown in Table 3. Only the LSIs calculated from the contact time and RSI during the SVCJs test were significantly lower in the post-ACLR athletes than in the healthy athletes.

Frequency distribution table analysis of post-ACLR athletes 
In this study, 75-80\% of the post-ACLR athletes had been judged "satisfactory" based on the LSIs from the singleleg hop tests. By contrast, only 25\% (5/21) had been judged "satisfactory" based on the LSI from the RSI during the SVCJs test (Table 4). Recovery of satisfactory RSI during the SVCJs test was associated with the symmetry of the single-leg hop tests. Of the patients who had an LSI $\geq 90 \%$ from the RSI during the SVCJs test, 100\% (5/5), 80\% (4/5), and 60\% (3/5) also had an LSI $\geq 90 \%$ for SHD, THD, and CHD, respectively.

Recovery in the single-leg hop tests was associated with the RSI during the SVCJs test. However, only 29.4\% (5/17), $23.5 \%(4 / 17)$, and $18.8 \%(3 / 16)$ of the athletes who had satisfactory recovery for SHD, THD, and CHD, respectively, had satisfactory recovery for RSI during the SVCJs test.

Table 2

Side-to-side differences for each test

\begin{tabular}{|c|c|c|c|c|c|c|c|c|}
\hline & \multicolumn{2}{|c|}{$\begin{array}{l}\text { Post-ACLR athletes }(n= \\
21)\end{array}$} & \multirow[b]{2}{*}{$\begin{array}{l}P \\
\text { value }\end{array}$} & \multirow[b]{2}{*}{$\begin{array}{l}\text { effect } \\
\text { size(d) }\end{array}$} & \multicolumn{3}{|c|}{ Healthy athletes $(n=17)$} & \multirow[b]{2}{*}{$\begin{array}{l}\text { effect } \\
\text { size(d) }\end{array}$} \\
\hline & $\begin{array}{l}\text { involved } \\
\text { limb } \\
\text { mean } \pm \\
\text { SD } \\
\text { (range) }\end{array}$ & $\begin{array}{l}\text { uninvolved } \\
\text { limb mean } \pm \\
\text { SD (range) }\end{array}$ & & & $\begin{array}{l}\text { poor- } \\
\text { performing } \\
\text { limb mean } \pm \\
\text { SD (range) }\end{array}$ & $\begin{array}{l}\text { well- } \\
\text { performing } \\
\text { limb mean } \pm \\
\text { SD (range) }\end{array}$ & $\begin{array}{l}P \\
\text { value }\end{array}$ & \\
\hline \multicolumn{9}{|l|}{ test } \\
\hline $\begin{array}{l}\text { SHD } \\
(\mathrm{cm})\end{array}$ & $\begin{array}{l}135.1 \pm \\
26.8 \\
(99.5- \\
191.5)\end{array}$ & $\begin{array}{l}138.9 \pm 28.9 \\
(103.0- \\
197.5)\end{array}$ & 0.269 & 0.14 & $\begin{array}{l}136.6 \pm 24.2 \\
(101.0- \\
188.5)\end{array}$ & $\begin{array}{l}143.6 \pm 26.6 \\
(103-197.5)\end{array}$ & $\begin{array}{l}< \\
0.001\end{array}$ & 0.28 \\
\hline $\begin{array}{l}\text { THD } \\
(\mathrm{cm})\end{array}$ & $\begin{array}{l}407.3 \pm \\
69.5 \\
(286.5- \\
57.5)\end{array}$ & $\begin{array}{l}429.3 \pm 72.2 \\
(315.0- \\
633)\end{array}$ & $\begin{array}{l}< \\
0.001\end{array}$ & 0.31 & $\begin{array}{l}451.4 \pm 66.9 \\
(365.0- \\
607.0)\end{array}$ & $\begin{array}{l}468.7 \pm 68.6 \\
(389.5- \\
614.5)\end{array}$ & $\begin{array}{l}< \\
0.001\end{array}$ & 0.26 \\
\hline $\begin{array}{l}\mathrm{CHD} \\
(\mathrm{cm})\end{array}$ & $\begin{array}{l}354.9 \pm \\
63.9 \\
(257.5- \\
493.0)\end{array}$ & $\begin{array}{l}379.2 \pm 73.6 \\
(261.0- \\
517.5)\end{array}$ & $\begin{array}{l}< \\
0.001\end{array}$ & 0.35 & $\begin{array}{l}400.2 \pm 70.1 \\
(293.5- \\
555.5)\end{array}$ & $\begin{array}{l}418.6 \pm 72.7 \\
(304.0- \\
556.5)\end{array}$ & $<.001$ & 0.26 \\
\hline $\begin{array}{l}\text { CT } \\
\text { during } \\
\text { SVCJs } \\
\text { (sec) }\end{array}$ & $\begin{array}{l}0.26 \pm \\
0.03 \\
(0.22- \\
0.33)\end{array}$ & $\begin{array}{l}0.25 \pm 0.02 \\
(0.21-0.30)\end{array}$ & $\begin{array}{l}<.001 \\
0.01\end{array}$ & 0.39 & $\begin{array}{l}0.24 \pm 0.02 \\
(0.19-0.27)\end{array}$ & $\begin{array}{l}0.24 \pm 0.02 \\
(0.19-0.27)\end{array}$ & 0.078 & 0.20 \\
\hline $\begin{array}{l}\text { JH } \\
\text { during } \\
\text { SVCJs } \\
\text { (cm) }\end{array}$ & $\begin{array}{l}10.2 \pm \\
2.5(6.3- \\
16.6)\end{array}$ & $\begin{array}{l}12.0 \pm 3.2 \\
(7.9-19.7)\end{array}$ & $\begin{array}{l}< \\
0.001\end{array}$ & 0.63 & $\begin{array}{l}12.6 \pm 3.6 \\
(7.1-22.46)\end{array}$ & $\begin{array}{l}13.6 \pm 3.5 \\
(8.4-22.2)\end{array}$ & 0.002 & 0.28 \\
\hline $\begin{array}{l}\text { RSI } \\
\text { during } \\
\text { SVCJs } \\
(\mathrm{cm} / \mathrm{s})\end{array}$ & $\begin{array}{l}38.8 \pm \\
9.5 \\
(25.4- \\
65.0)\end{array}$ & $\begin{array}{l}48.4 \pm 11.4 \\
(26.6-73.0)\end{array}$ & $\begin{array}{l}<.001 \\
0.001\end{array}$ & 0.92 & $\begin{array}{l}52.3 \pm 13.7 \\
(27.9-88.2)\end{array}$ & $\begin{array}{l}57.7 \pm 14.0 \\
(33.5-90.5)\end{array}$ & 0.002 & 0.39 \\
\hline
\end{tabular}

ACLR, anterior cruciate ligament reconstruction; SD, standard deviation; SHD, single hop for distance; THD, triple hop for distance; CHD, crossover hop for distance; CT, contact time; SVCJs, single-leg vertical continuous jumps; $\mathrm{JH}$, jump height; $\mathrm{RSI}$, reactive strength index 
Table 3

Limb symmetry index for each test

\begin{tabular}{|lllll|}
\hline & $\begin{array}{l}\text { Post-ACLR athletes }(\mathbf{n = 2 1}) \\
\text { mean } \pm \text { SD (range) }\end{array}$ & $\begin{array}{l}\text { Healthy subjects }(\mathbf{n = 1 7 )} \\
\text { mean } \pm \text { SD (range) }\end{array}$ & p Value & effect size (d) \\
\hline SHD (\%) & $95.1 \pm 6.8(85.3-117.9)$ & $95.6 \pm 2.5(91.1-99.7)$ & 0.781 & 0.09 \\
\hline THD (\%) & $95.0 \pm 5.5(83.7-108.3)$ & $95.7 \pm 3.6(87.9-99.3)$ & 0.626 & 0.15 \\
\hline CHD (\%) & $93.9 \pm 5.8(82.1-103.7)$ & $96.1 \pm 2.4(92.3-99.9)$ & 0.126 & 0.48 \\
\hline CT during SVCJs (\%) & $106.7 \pm 4.9(95.2-113.9)$ & $102.1 \pm 4.6(95.1-115.0)$ & 0.006 & 0.96 \\
\hline JH during SVCJs (\%) & $86.5 \pm 12.9(66.9-120.3)$ & $93.2 \pm 7.4(76.7-104.1)$ & 0.90 & 0.62 \\
\hline RSI during SVCJs (\%) & $81.4 \pm 14.8(58.0-125.5)$ & $91.9 \pm 6.2(82.3-104.0)$ & 0.006 & 0.89 \\
\hline $\begin{array}{l}\text { ACLR, anterior cruciate ligament reconstruction; SD, standard deviation; SHD, single hop for distance; THD, triple } \\
\text { hop for distance; CHD, crossover hop for distance; CT, contact time; SVCJs, single-leg vertical continuous } \\
\text { jumps; JH, jump height; RSI, reactive strength index. }\end{array}$ & & & \\
\hline \begin{tabular}{l} 
Statiscally significant difference: $p<0.05$ \\
\hline
\end{tabular}
\end{tabular}

Table 4

Association of the single-leg hop tests with the RSI during the SVCJs test in post-ACLR athletes

\begin{tabular}{|c|c|c|c|c|c|c|c|c|c|c|c|c|c|}
\hline \multicolumn{6}{|c|}{ SHD } & \multicolumn{4}{|l|}{ THD } & \multicolumn{4}{|l|}{ CHD } \\
\hline & LSI & $\geq 0 \%$ & $<50 \%$ & Sum & $\begin{array}{l}P \\
\text { value }\end{array}$ & $\geq 9$ & $<{ }_{90 \%}$ & Sum & $\begin{array}{l}P \\
\text { value }\end{array}$ & $\geq 9$ & $<50 \%$ & Sum & $\begin{array}{l}P \\
\text { value }\end{array}$ \\
\hline $\begin{array}{l}\text { RSI } \\
\text { during }\end{array}$ & $\geq 0 \%$ & 5 & 0 & 5 & $<.01$ & 4 & 1 & 5 & $<.01$ & 3 & 2 & 5 & $<01$ \\
\hline \multirow[t]{2}{*}{ SVCJ } & $<$ & 12 & 4 & 16 & & 13 & 3 & 16 & & 13 & 3 & 16 & \\
\hline & Sum & 17 & 4 & 21 & & 17 & 4 & 21 & & 16 & 5 & 21 & \\
\hline \multicolumn{14}{|c|}{$\begin{array}{l}\text { RSI, reactive strength index; SVCJs, single-leg vertical continuous jumps; ACLR, anterior cruciate ligament } \\
\text { reconstruction; SHD, single hop for distance; THD, Triple hop for distance; CHD, crossover hop for distance. }\end{array}$} \\
\hline
\end{tabular}

\section{Discussion}

In this study, the scores of the RSI during SVCJs and single-leg hop tests, except for the SHD, were significantly lower on the involved limb than on the uninvolved limb in post-ACLR athletes, and they showed the largest effect size for the difference in the RSI during SVCJs. No significant difference was found in the LSIs of single-leg hop tests between post-ACLR and healthy athletes. By contrast, the RSI during SVCJs was significantly lower in postACLR athletes than in healthy athletes, and the effect size was large. Among post-ACLR athletes, less than $30 \%$ of 
those with LSIs above $90 \%$ in the single-leg hop tests had LSIs above $90 \%$ in the RSI during SVCJs. These results support our hypotheses, except for the difference in the LSIs between the groups in the single-leg hop tests.

Gokeler et al. reported a significant difference in SHD measurements between the involved and uninvolved limbs of post-ACLR athletes [27]. Herrinton et al. reported similar findings for the THD and CHD measurements with a moderate effect size [28]. These studies have reported a duration of 6.7-7.8 months since reconstruction in postACLR athletes. Our study contradicts these findings and reports a mean duration of $11.6(6.7-31.2)$ months. The LSIs of the single-leg hop tests that measure distance increased as duration increased after reconstruction [29]. The longer duration after reconstruction in our study may have influenced the difference observed in the results between the present study and previous studies. The LSIs of the single-leg hop tests showed that post-ACLR athletes who had undergone reconstruction approximately 11 months earlier recovered to the same level as healthy athletes.

In this study, the RSI during SVCJs was significantly lower on the involved limb than on the uninvolved limb of post-ACLR athletes and had a large effect size. Their corresponding LSIs were significantly lower than that of healthy athletes, and the effect size was large. Myer et al. reported that the mean LSI of the jump height of postACLR athletes was $89 \%$ [10]. Similarly, the mean jump height and RSI during SVCJs in the present study was $86 \%$ and $81 \%$, respectively. The study findings show that greater lower limb asymmetry can be detected by calculating the RSI with the jump height and contact time. In many previous studies that have assessed jump with landing and leaping for healthy athletes, the contact time and RSI have been used as parameters of jump performance [30, 31]. The RSI for continuous vertical jumps in post-ACLR athletes is not known. Our study results therefore provide new insights into the RSI during SVCJs in post-ACLR athletes who are determining the appropriate timing to return to sport.

Less than $30 \%$ of the post-ACLR athletes with an LSI of $90 \%$ or above in the single-leg hop tests had an LSI over $90 \%$ in the RSI during SVCJs. The results of this study showed that the symmetry of single-leg forward hop performance was restored in post-ACLR athletes more than 6 months after surgery, but asymmetry remained in their reactive continuous vertical jump performance. According to a study that analyzed the LSIs of the jump height during SVCJS, SHD, and THD in post-ACLR athletes 54 weeks after reconstruction, the LSI of the jump height during SVCJs was the lowest, which is similar to our study findings [32]. The present results support our hypothesis. For post-ACLR athletes at the phase of determining the timing of their return to sport, the RSI during SVCJs was shown to detect lower limb asymmetry more easily than the single-leg hop tests.

In our study, a side-to-side difference was found in the single-leg hop tests and RSI during SVCJs in both post-ACLR and healthy athletes. In healthy athletes, the LSI for each test ranged from 91.9-96.5\%. Several studies have reported no or small side-to-side differences in single-leg hop tests in healthy athletes [33, 34]. A difference was found in the methods of LSI calculations, and various definitions were used to categorize the lower limbs between the studies. Some studies mostly analyzed the differences and ratios between the dominant and non-dominant limbs separately in healthy athletes $[33,35,36]$. Our study divided the lower limbs of healthy athletes into poorperforming and well-performing limbs. Therefore, we observed a greater difference when comparing the dominant and non-dominant limbs. In our study, the LSI was calculated using results of the poor-performing limb as the numerator and results of the well-performing limb as the denominator, which was effective in identifying the asymmetry in the limbs. 
Single-leg hop tests are a forward jumping test, but SVCJs are continuous jumps in the vertical direction. Vertical jumps are frequently required in sports such as basketball, handball, and volleyball, which record a high incidence of ACL injuries [37-39]. A pre-return to sport vertical jump performance assessment may be useful for post-ACLR athletes participating in these sporting events. However, vertical jumping tasks are less frequently used than horizontal jumping tasks such as the single-leg hop tests in assessing post-ACLR athletes [40]. To ensure return to sport in post-ACLR athletes participating in sports that require frequent vertical jumps, evaluations related to vertical jumps would need to be included in the return to sport criteria.

A recent systematic review identified the need for modification of return to sport criteria for adequate decision making regarding the timing of return to sport in post-ACLR athletes [40,41]. Even if a test is able to accurately capture an athlete's recovery status, generalization is difficult if it is not feasible in a clinical setting. Recent advances in technology have made it possible for relatively inexpensive devices such as mat switches [42] and smartphone applications [43] to accurately measure flight time and RSI for vertical jumps involving landing and leaping. The RSI during SVCJs employed in this study has the following advantages as a functional assessment of post-ACLR athletes. First, similar to the single-leg hop tests, this is a single-legged task; therefore, the asymmetry of the lower limb function can be confirmed. Second, SVCJs can be performed in a relatively space-saving manner. The results of this study indicate that the RSI during SVCJs may serve as a new indicator for detecting lower extremity asymmetry in post-ACLR athletes at the phase of determining the timing of their return to sport.

This study has several limitations. First, although sex influences the effect of lower body explosiveness on jump landings as assessed by the RSI [44], it was not included in the analysis. Approximately $70 \%$ of the study participants were female. Second, the surgical technique for inclusion was not limited. Third, because the study included post-ACLR athletes who were within 6 months to 2 years after surgery, the return to sport status varied, but it was not analyzed separately for timing or return to sport status. Finally, we only used the Optojump ${ }^{\mathrm{TM}}$ system for the RSI during SVCJs measurements. In RSI measurements, fixed bias may occur due to differences in measurement equipment [19]. Therefore, careful attention is needed when comparing the data from this study with studies that have used different measuring instruments.

\section{Conclusion}

The RSI during SVCJs on the involved side 6 months after reconstruction was significantly lower than that on the uninvolved side of post-ACLR athletes, and the asymmetry was more remarkable in the SVCJs than in the singleleg hop tests. Among the post-ACLR athletes who recovered the asymmetry in the single-leg hop tests, most had residual asymmetry in the RSI during SVCJs. These findings will assist in selecting an appropriate jumping performance test, which is an important component of the return to sport criteria for determining the timing of an athlete's return to sport.

\section{Abbreviations}

Reactive strength index (RSI)

Single-leg vertical continuous jumps (SVCJs)

Anterior cruciate ligament $(A C L)$

Anterior cruciate ligament reconstruction (ACLR)

Page 11/15 
Limb symmetry index (LSI)

Single hop for distance (SHD)

Triple hop for distance (THD)

Crossover hop for distance (CHD)

Limb symmetry index (LSI)

\section{Declarations}

Ethics approval and consent to participate: All experimental procedures of the present study were approved by the Institutional Review Board of Tokyo Medical and Dental University and were conducted according to the Declaration of Helsinki (approval number: M2017-077). All participants provided written informed consent before participation. In the case of minor participants (between 16 and 19 years old), informed consent was obtained from their parents/legal guardians.

Consent for publication: Not applicable

Availability of data and materials: The datasets used and/or analysed during the current study are available from the corresponding author on reasonable request.

Competing interests: The authors certify that there are no conflicts of interest with any financial organization regarding the material discussed in the manuscript.

Funding: This work was supported by JSPS KAKENHI Grant Number JP17K13050.

Authors' contributions: $\mathrm{KH}$ and JA contributed substantially to the conception or design of the manuscript, $\mathrm{KH}, \mathrm{TO}$, SO, SM, and TO contributed substantially to the acquisition, analysis and interpretation of the data. All authors participated in drafting the manuscript. HK, KY, TJ, and AO revised the manuscript critically. All authors contributed equally to the manuscript and read and approved the final version of the manuscript.

Acknowledgements: The authors thank all the participants who were included in this study. We would like to thank Editage [https://www.editage.jp/] for editing and reviewing this manuscript for English language.

\section{References}

1. Ardern CL, Glasgow P, Schneiders A, Witvrouw E, Clarsen B, Cools A, et al. 2016 Consensus statement on return to sport from the First World Congress in Sports Physical Therapy, Bern. Br J Sports Med. 2016;50:853-64. https://doi.org/10.1136/bjsports-2016-096278.

2. Lynch AD, Logerstedt DS, Grindem H, Eitzen I, Hicks GE, Axe MJ, et al. Consensus criteria for defining 'successful outcome' after ACL injury and reconstruction: A Delaware-Oslo ACL cohort investigation. Br J Sports Med. 2015;49:335-42. https://doi.org/10.1136/bjsports-2013-092299.

3. Rambaud AJM, Ardern CL, Thoreux P, Regnaux JP, Edouard P. Criteria for return to running after anterior cruciate ligament reconstruction: A scoping review. Br J Sports Med. 2018;52:1437-44.

https://doi.org/10.1136/bjsports-2017-098602.

Page $12 / 15$ 
4. Logerstedt D, Grindem H, Lynch A, Eitzen I, Engebretsen L, Risberg MA, et al. Single-legged hop tests as predictors of self-reported knee function after anterior cruciate ligament reconstruction: the Delaware-Oslo ACL cohort study. Am J Sports Med. 2012;40:2348-56. https://doi.org/10.1177/0363546512457551.

5. Reid A, Birmingham TB, Stratford PW, Alcock GK, Giffin JR. Hop testing provides a reliable and valid outcome measure during rehabilitation after anterior cruciate ligament reconstruction. Phys Ther. 2007;87:337-49. https://doi.org/10.2522/ptj.20060143.

6. Noyes FR, Barber SD, Mangine RE. Abnormal lower limb symmetry determined by function hop tests after anterior cruciate ligament rupture. Am J Sports Med. 1991;19:513-8. https://doi.org/10.1177/036354659101900518.

7. Thomeé R, Neeter C, Gustavsson A, Thomeé P, Augustsson J, Eriksson B, et al. Variability in leg muscle power and hop performance after anterior cruciate ligament reconstruction. Knee Surg Sports Traumatol Arthrosc. 2012;20:1143-51. https://doi.org/10.1007/s00167-012-1912-y.

8. Gustavsson A, Neeter C, Thomeé P, Silbernagel KG, Augustsson J, Thomeé R, et al. A test battery for evaluating hop performance in patients with an ACL injury and patients who have undergone ACL reconstruction. Knee Surg Sports Traumatol Arthrosc. 2006;14:778-88. https://doi.org/10.1007/s00167-006-0045-6.

9. Kyritsis P, Bahr R, Landreau P, Miladi R, Witvrouw E. Likelihood of ACL graft rupture: Not meeting six clinical discharge criteria before return to sport is associated with a four times greater risk of rupture. Br J Sports Med. 2016;50:946-51. https://doi.org/10.1136/bjsports-2015-095908.

10. Myer GD, Martin L, Ford KR, Paterno MV, Schmitt LC, Heidt RS, et al. No association of time from surgery with functional deficits in athletes after anterior cruciate ligament reconstruction: Evidence for objective return-tosport criteria. Am J Sports Med. 2012;40:2256-63. https://doi.org/10.1177/0363546512454656.

11. Harrison AD, Ford KR, Myer GD, Hewett TE. Sex differences in force attenuation: A clinical assessment of single-leg hop performance on a portable force plate. Br J Sports Med. 2011;45:198-202. https://doi.org/10.1136/bjsm.2009.061788.

12. Scanlan A, Dascombe B, Reaburn P. A comparison of the activity demands of elite and sub-elite Australian men's basketball competition. J Sports Sci. 2011;29:1153-60.

https://doi.org/10.1080/02640414.2011.582509.

13. Skazalski C, Whiteley R, Bahr R. High jump demands in professional volleyball-large variability exists between players and player positions. Scand J Med Sci Sports. 2018;28:2293-8. https://doi.org/10.1111/sms.13255.

14. Abrams GD, Harris JD, Gupta AK, McCormick FM, Bush-Joseph CA, Verma NN, et al. Functional performance testing After anterior cruciate ligament reconstruction: A systematic review. Orthop J Sports Med. 2014;2:2325967113518305. https://doi.org/10.1177/2325967113518305.

15. Barber-Westin SD, Noyes FR. Factors used to determine return to unrestricted sports activities after anterior cruciate ligament reconstruction. Arthroscopy. 2011;27:1697-705.

https://doi.org/10.1016/j.arthro.2011.09.009.

16. Miura K, Yamamoto M, Tamaki H, Zushi K. Determinants of the abilities to jump higher and shorten the contact time in a running 1-legged vertical jump in basketball. J Strength Cond Res. 2010;24:201-6. https://doi.org/10.1519/JSC.0b013e3181bd4c3e.

17. Kollias I, Hatzitaki V, Papaiakovou G, Giatsis G. Using principal components analysis to identify individual differences in vertical jump performance. Res Q Exerc Sport. 2001;72:63-7.

https://doi.org/10.1080/02701367.2001.10608933.

Page 13/15 
18. Flanagan EP, Ebben WP, Jensen RL. Reliability of the reactive strength index and time to stabilization during depth jumps. J Strength Cond Res. 2008;22:1677-82. https://doi.org/10.1519/JSC.0b013e318182034b.

19. Healy R, Kenny IC, Harrison AJ. Assessing reactive strength measures in jumping and hopping using the Optojump ${ }^{\mathrm{TM}}$ system. J Hum Kinet. 2016;54:23-32. https://doi.org/10.1515/hukin-2016-0032.

20. Fältström A, Hägglund M, Kvist J. Patient-reported knee function, quality of life, and activity level after bilateral anterior cruciate ligament injuries. Am J Sports Med. 2013;41:2805-13. https://doi.org/10.1177/0363546513502309.

21. Bolgla LA, Keskula DR. Reliability of lower extremity functional performance tests. J Orthop Sports Phys Ther. 1997;26:138-42. https://doi.org/10.2519/jospt.1997.26.3.138.

22. Bosco C, Luhtanen P, Komi PV. A simple method for measurement of mechanical power in jumping. Eur J Appl Physiol Occup Physiol. 1983;50:273-82. https://doi.org/10.1007/BF00422166.

23. Glatthorn JF, Gouge S, Nussbaumer S, Stauffacher S, Impellizzeri FM, Maffiuletti NA. Validity and reliability of Optojump photoelectric cells for estimating vertical jump height. J Strength Cond Res. 2011;25:556-60. https://doi.org/10.1519/JSC.0b013e3181ccb18d.

24. Byrne DJ, Browne DT, Byrne PJ, Richardson N. Interday reliability of the reactive strength index and optimal drop height. J Strength Cond Res. 2017;31:721-6. https://doi.org/10.1519/JSC.0000000000001534.

25. Munro AG, Herrington LC. Between-session reliability of four hop tests and the agility T-test. J Strength Cond Res. 2011;25:1470-7. https://doi.org/10.1519/JSC.0b013e3181d83335.

26. Zwolski C, Schmitt LC, Thomas S, Hewett TE, Paterno MV. The utility of limb symmetry indices in return-tosport assessment in patients with bilateral anterior cruciate ligament reconstruction. Am J Sports Med. 2016;44:2030-8. https://doi.org/10.1177/0363546516645084.

27. Gokeler A, Welling W, Benjaminse A, Lemmink K, Seil R, Zaffagnini S. A critical analysis of limb symmetry indices of hop tests in athletes after anterior cruciate ligament reconstruction: A case control study. Orthop Traumatol Surg Res 2017;103(6):947-51. https://doi.org/10.1016/j.otsr.2017.02.015.

28. Herrington L, Ghulam H, Comfort P. Quadriceps strength and functional performance after anterior cruciate ligament reconstruction in professional soccer players at time of return to sport. J Strength Cond Res. 2021;35:769-75. https://doi.org/10.1519/JSC.0000000000002749.

29. Curran MT, Bedi A, Kujawa M, Palmieri-Smith R. A cross-sectional examination of quadriceps strength, biomechanical function, and functional performance from 9 to 24 months after anterior cruciate ligament reconstruction. Am J Sports Med. 2020;48:2438-46. https://doi.org/10.1177/0363546520940310.

30. Gahreman D, Moghadam MA, Hoseininejad E, Dehnou VV, Connor JD, Doma K, et al. Postactivation potentiation effect of two lower body resistance exercises on repeated jump performance measures. Biol Sport. 2020;37:105-12. https://doi.org/10.5114/biolsport.2020.93034.

31. Jeffreys MA, De Ste Croix MBA, Lloyd RS, Oliver JL, Hughes JD. The effect of varying plyometric volume on stretch-shortening cycle capability in collegiate male rugby players. J Strength Cond Res. 2019;33:139-45. https://doi.org/10.1519/JSC.0000000000001907.

32. Petschnig R, Baron R, Albrecht M. The relationship between isokinetic quadriceps strength test and hop tests for distance and one-legged vertical jump test following anterior cruciate ligament reconstruction. J Orthop Sports Phys Ther. 1998;28:23-31. https://doi.org/10.2519/jospt.1998.28.1.23.

33. Onate JA, Starkel C, Clifton DR, Best TM, Borchers J, Chaudhari A, et al. Normative functional performance values in high school athletes: The functional pre-participation evaluation project. J Athl Train. 2018;53:35-

Page $14 / 15$ 
42. https://doi.org/10.4085/1062-6050-458.16.

34. Blakeney WG, Ouanezar H, Rogowski I, Vigne G, Guen ML, Fayard JM, et al. Validation of a composite test for assessment of readiness for return to sports after anterior cruciate ligament reconstruction: The K-STARTS test. Sports Health. 2018;10:515-22. https://doi.org/10.1177/1941738118786454.

35. Greenberg EM, Dyke J, Leung A, Karl M, Lawrence JT, Ganley T. Uninjured youth athlete performance on singleleg hop testing: How many can achieve recommended return-to-sport criterion? Sports Health. 2020:1941738120911662;12:552-8. https://doi.org/10.1177/1941738120911662.

36. Myers BA, Jenkins WL, Killian C, Rundquist P. Normative data for hop tests in high school and collegiate basketball and soccer players. Int J Sports Phys Ther. 2014;9:596-603.

37. Gornitzky AL, Lott A, Yellin JL, Fabricant PD, Lawrence JT, Ganley TJ. Sport-specific yearly risk and incidence of anterior cruciate ligament tears in high school athletes: A systematic review and meta-analysis. Am J Sports Med. 2016;44:2716-23. https://doi.org/10.1177/0363546515617742.

38. Agel J, Rockwood T, Klossner D. Collegiate ACL injury rates across 15 sports: National Collegiate Athletic Association injury surveillance system data update (2004-2005 through 2012-2013). Clin J Sport Med. 2016;26:518-23. https://doi.org/10.1097/JSM.0000000000000290.

39. Natali S, Ferioli D, La Torre A, Bonato M. Physical and technical demands of elite beach volleyball according to playing position and gender. J Sports Med Phys Fitness. 2019;59:6-9. https://doi.org/10.23736/S00224707.17.07972-5.

40. Burgi CR, Peters S, Ardern CL, Magill JR, Gomez CD, Sylvain J, et al. Which criteria are used to clear patients to return to sport after primary ACL reconstruction? A scoping review. Br J Sports Med. 2019;53:1154-61. https://doi.org/10.1136/bjsports-2018-099982.

41. Losciale JM, Zdeb RM, Ledbetter L, Reiman MP, Sell TC. The association between passing return-to-sport criteria and second anterior cruciate ligament injury risk: A systematic review with meta-analysis. J Orthop Sports Phys Ther. 2019;49:43-54. https://doi.org/10.2519/jospt.2019.8190.

42. Rantalainen T, Hesketh KD, Rodda C, Duckham RL. Validity of hip-worn inertial measurement unit compared to jump mat for jump height measurement in adolescents. Scand J Med Sci Sports. 2018;28:2183-8. https://doi.org/10.1111/sms.13243.

43. Haynes T, Bishop C, Antrobus M, Brazier J. The validity and reliability of the My Jump 2 app for measuring the reactive strength index and drop jump performance. J Sports Med Phys Fitness. 2019;59:253-8. https://doi.org/10.23736/S0022-4707.18.08195-1.

44. Beckham GK, Suchomel TJ, Sole CJ, Bailey CA, Grazer JL, Kim SB, et al. Influence of sex and maximum strength on reactive strength index-modified. J Sports Sci Med. 2019;18:65-72. 